\title{
Método com abordagem participativa para análise de usabilidade do site SENAI EAD
}

\section{Method with participative approach for usability analysis of the SENAI EAD website}

Priscila Câmara Reis ${ }^{1}$

Helena Rugai Bastos ${ }^{2}$ 


\section{Resumo}

O artigo apresenta um método adaptado para avaliação de usabilidade do cadastro e primeiro acesso ao curso de Empreendedorismo oferecido pelo portal SENAI EAD. É resultado de pesquisa maior, que compreende estudos e articulações entre conceitos e fundamentos sobre Design Instrucional, Educação a Distância, Design de Interação, Design Centrado no Usuário, e métodos e processos de avaliação de usabilidade. A partir da análise dos materiais e dos processos, foi desenvolvido o método de avaliação de usabilidade, baseado em ferramentas adotadas em abordagens participativas, que incluem os usuários no processo. Assim, apresenta descrição e aplicação do método proposto para tal avaliação.

Palavras-chave: EAD; usabilidade; design participativo; usuário.

\section{Abstract}

This article presents an adapted method for registration and first access usability to the Entrepreneurship online course offered by SENAI EAD Portal. It results a major research that consists studies and articulations among concept and fundaments of Instructional Design, Distance Education, Interaction Design, User-centered Design by methods and processes of usability evaluation. According to the analysis from materials and processes, it was developed a method of usability evaluation based on participative approaches adopted tools which include the user in the process. Therefore, it presents the description and application purposed by it evaluation.

Keywords: distance education; usability; participatory design approaches; user.

ISSN: 2316-7963

1'Bacharel em Design, UFRN (priscila.camarareis@gmail.com)

2 Doutora, UFRN (helenarugai@gmail.com) 


\section{Introdução}

O termo Educação é definido no dicionário Novo Aurélio Século XXI, como: "ato ou efeito de educar (se). [...] é um processo de desenvolvimento da capacidade física, intelectual e moral da criança e do ser humano em geral, visando a melhor integração individual e social" (FERREIRA, 1999). Pode-se considerar que a aprendizagem, de acordo com Vygotsky (1987), não é somente um processo de aquisição de informações e não acontece pela simples associação de ideias armazenadas na memória, e sim um processo interno, ativo e interpessoal. A partir deste princípio, classificam-se processos e estratégias cognitivas, como os meios pelos quais o aluno organiza e administra seus processos cognitivos para aprendizagem, atenção e memória (NETO, ANACLETO \& NERIS, 2005).

No entanto, o atual momento é de transformação, uma vez que os modelos presentes na educação tradicional carecem de alternativas diante das necessidades e dos desafios contemporâneos. Filatro (2004), afirma que muito se tem estudado sobre a necessidade emergente de novos parâmetros educacionais, tendo em vista as constantes mudanças econômicas, políticas, sociais e culturais ocorridas nos últimos tempos. Isso se dá em resposta ao decorrente desenvolvimento científico e tecnológico da era da informação. Desta maneira, falar sobre educação em qualquer aspecto nos dias atuais implica em falar também de macro fenômenos relacionados, que marcam uma quebra de paradigmas. Por conseguinte, a globalização e a informatização denotam um novo tipo de sociedade, denominadas sociedade da informação ou do conhecimento.

Nessa atual sociedade em rede, aprender caracteriza-se por uma apropriação de conhecimento que se dá numa realidade concreta, isto é, parte-se da situação real vivida pelo educando, o que é apoiado pela presença mediadora e gestora de um professor. Este professor, compromissado com seus alunos e com a construção de conhecimentos, procura responder ao princípio da aprendizagem significativa (CASTELLS, 2012). Nessa perspectiva, o aluno se torna personagem principal do seu processo de aprendizagem, e o conhecimento é concebido como resultado da ação do sujeito sobre a realidade (BEHAR, 2009, p. 16).

De acordo com Morán (2015), o avanço tecnológico e o fácil acesso à informação têm modificado a maneira de transmissão de conhecimento entre educador e aluno. Ele entende que a sala de aula não é mais somente um espaço físico, mas um espaço ampliado, que se mescla diretamente com o mundo digital. Exemplo disso ocorre com a incorporação de novas tecnologias de comunicação, as quais possibilitaram o desenvolvimento dos cursos de Ensino a Distância em Ambientes Virtuais de Aprendizagem [AVA].

A necessidade de se estudar modalidades de ensino a distância mediadas pela tecnologia, justifica-se como uma maneira de minimizar questões sobre acesso ao ensino, que envolve o número de vagas oferecidas pelas redes de ensino, que são restritas, e a necessidade de incluir socialmente uma maior parcela de alunos. Além disso, é necessário levar em conta as exigências individuais e sociais às novas demandas do mercado de trabalho, comunicação e informação (FILATRO, 2004).

A expansão da EAD, a incorporação de tecnologias de informação e comuni- 
cação nos mais diferentes níveis e modalidades de educação torna cada vez mais nítidas a necessidade de profissionalizar aqueles que trabalham diretamente na criação de soluções para o aprendizado eletrônico (FILATRO, 2008). O padrão mínimo de qualidade em tais cursos é fundamental, tanto na produção quanto na metodologia abordada nos materiais, haja vista a aquisição de conhecimento ser realizada pelo aluno, apoiada pelo o professor como um mediador de conhecimento, como citado anteriormente (CASTELLS, 2012). Logo, essas abordagens devem ser baseadas em aspectos que proporcionem a facilidade de uso e, consequentemente, a melhor aceitação por parte do discente.

É nesse contexto que o Design Instrucional está inserido. Design Instrucional ou Design de Aprendizagem define-se como uma ação intencional e sistemática, que envolve planejamento, desenvolvimento e aplicação de técnicas, a fim de promover a aprendizagem humana (FILATRO, 2008). Embora o uso mais comum esteja voltado à Educação Corporativa, seus princípios são aplicáveis a qualquer contexto em que exista a aquisição de conhecimentos ou de habilidades.

É impossível abordar Design Instrucional [DI] sem correlacioná-lo a temas como usabilidade, Design de Interação, Design Centrado no Usuário [DCU] e Experiência do Usuário. Isso se dá pelo fato de que prática do DI tem sido, cada vez mais frequente, no que diz respeito ao modo com que os materiais educacionais de EAD estão sendo projetados. Incluir os usuários em processos de design é fundamental para um material de boa qualidade, além de oferecer diversas possibilidades para uma aprendizagem significativa. Ademais, a usabilidade deve ser considerada como um dos temas de maior relevância no contexto, tendo em vista a sua principal finalidade, que é a aceitação desse material ou sistema por parte dos usuários.

Nesse sentido, o artigo apresenta método adaptado para avaliação de usabilidade, a partir de abordagem participativa, do portal SENAI EAD, em particular, a etapa de cadastro e o primeiro acesso a um curso oferecido neste ambiente. A investigação maior compreende o estudo e as articulações entre conceitos e fundamentos sobre Design Instrucional, Educação a Distância, Design de Interação, Design Centrado no Usuário, métodos e processos de avaliação de usabilidade, abordagens participativas, princípios da linguagem visual. A partir do estudo e da análise dos materiais e dos processos levantados, foi adaptado e aplicado método de avaliação de usabilidade, baseado em ferramentas adotadas em abordagens participativas, que incluem os usuários no processo. Este trabalho apresenta a aplicação do método proposto para avaliação, os resultados desta etapa da pesquisa e a análise dos dados. O processo permitiu elaborar recomendações para a melhoria do primeiro acesso ao AVA estudado.

\section{Objeto de estudo}

Para o estudo de usabilidade, optou-se por analisar o curso online de Empreendedorismo disponibilizado no Portal do Serviço Nacional de Aprendizagem Industrial [SENAI]. O SENAI foi criado em 1942. Sobretudo na década de 1950, observou um rápido desenvolvimento e crescimento. Hoje, a instituição é um dos mais consolidados complexos educacionais da América Latina e investe, de maneira constante, em EAD, 
para ampliar a oferta de cursos técnicos de nível médio e cursos de qualificação profissional (SENAI, Online). O objetivo da EAD na instituição, é o desenvolvimento de capacidades e atualização do conhecimento, para quem está ou quer entrar no mercado de trabalho.

De acordo com o Portal da Indústria, o curso de Empreendedorismo "apresenta características fundamentais para se tornar um empreendedor e a conquistar maior espaço em um mundo cada dia mais competitivo" (2016, online). Ele é destinado a "profissionais, estudantes ou demais pessoas que visam buscar conhecimentos sobre empreendedorismo". A proposta de avaliar o cadastro e primeiro acesso dos usuários ao curso EAD originou-se devido ao fato de que, muitas vezes o acesso ao curso, que deveria ser algo simples e objetivo, torna-se uma atividade confusa e exaustiva. Além de muitos passos para o cadastro e o acesso ao material do curso, os sistemas apresentam erros, que tornam a primeira etapa cansativa para o aluno, o usuário. A falta de intimidade com o sistema e a incompreensão sobre os procedimentos que devem ser realizados para acessar o material de estudo acarretam insegurança, dificuldades de memorização, uso exagerado de carga cognitiva para assimilar o conteúdo, desinteresse e, finalmente a desistência.

Por isso, para a avaliação do sistema mencionado, foram selecionados estudantes de graduação de Design da (nome da universidade) com idade entre 19 e 21 anos, com interesse na área de empreendedorismo e ligados, de alguma maneira, à indústria ou ao comércio do município de (nome da cidade). Deste modo, reuniu-se uma parcela de usuários que, além de estarem inseridos no mercado de trabalho da cidade, contribuíram significativamente para a pesquisa.

\section{Fundamentação teórica}

A pesquisa compreendeu o estudo sobre conceitos e fundamentos de EAD, Design Instrucional [DI], Design de Interação, Design Centrado no Usuário [DCU], métodos e processos de avaliação de usabilidade, abordagens participativas e princípios da linguagem visual. Após essa fundamentação, foi possível levar em conta estes conceitos a fim de articula-los na criação do método de avaliação proposto no estudo.

\subsection{Educação a Distância no Brasil e as novas Tecnologias de Informação e Comunicação}

A necessidade de compreender modalidades de EAD mediadas pela tecnologia justifica-se como uma maneira de minimizar questões sobre acesso ao ensino, que envolve o número de vagas oferecidas pelas redes de ensino, que são restritas, e a necessidade de incluir socialmente uma maior parcela de alunos. Além disso, é necessário levar em conta as exigências individuais e sociais às novas demandas do mercado de trabalho, comunicação e informação (FILATRO, 2004).

Para esta pesquisa, é importante observar o conceito de Educação a Distância sob a ótica da tecnologia, pois esta é vertente abordada no estudo. Como classifica Chaves (1999 apud Alves 2011), no sentido fundamental da expressão, a EAD é o 
ensino que ocorre quando o professor e o aluno estão separados no tempo ou no espaço. Desta forma, ele enfatiza a distância no espaço e propõe que ela seja contornada por meio do uso de tecnologias de telecomunicação e de transmissão de dados, voz e imagens. Ademais, não é preciso ressaltar que todas essas tecnologias, hoje, convergem para o computador. (ALVES, 2011, p. 85).

Fazendo um breve abarque histórico sobre a EAD no Brasil, podemos observar que, inicialmente, a Educação a Distância é apresentada como uma modalidade de ensino que acompanhou o desenvolvimento do sistema educacional brasileiro e, a partir de 1996, recebeu significativo apoio do Governo Federal. Esse apoio foi dado por meio do Ministério da Educação, o qual vem incentivando, mesmo que a passos lentos, o seu crescimento tanto na esfera púbica quanto privada (MUGNOL, 2009).

Atualmente, a expansão da Educação s Distância é uma realidade incontestável no Brasil. Segundo dados do censo realizado pela Associação Brasileira de Educação a Distância - ABED, 15,8\% dos alunos matriculados em cursos de graduação no Brasil são $E A D$, isso representa mais de um milhão de alunos estudando a distância. Além disso, o perfil predominante dos alunos EAD no Brasil é de mulheres entre 31 a 40 anos, que estudam e trabalham. (EAD, Online). Isso mostra como a EAD estabelece pontes de ensino que antes não poderiam ser construídas, e que, sem dúvidas, foram proporcionadas pelo o avançado das Tecnologias da Informação e Comunicação.

Porém, apesar do constante progresso, muitas lacunas no contexto da EAD precisam ser discutidas e preenchidas. Podemos destacar como pontos ainda controversos: a forma de transmissão, os provedores da tecnologia, a população-alvo dos cursos ofertados, a formação e organização dos projetos pedagógicos, os métodos de avaliação de aprendizagem, entre tantos outros. (MUGNOL, 2009). É válido ressaltar, neste estudo, que a proposta de avaliação de cadastro e acesso a um curso EAD se enquadra num método de avaliação de aprendizagem, pois um material fácil de ser acessado é um dos fatores que proporcionam uma aprendizagem significativa. Assim, o trabalho está inserido dentro do contexto da EAD como uma ferramenta que propõe mudanças e discursões sobre temas ainda pouco debatidos.

Além disso, cabe ainda se discutir o papel imprescindível que as Tecnologias da Informação e Comunicação (TIC) estão desenvolvendo no contexto do ensino a distância. Segundo Rezende $(2002$, p. 6) as principais características das TIC presentes nos materiais didáticos são as possibilidades de: interatividade; simulação de aspectos da realidade por meio do computador; interação entre sujeitos da relação ensino aprendizagem a distância; armazenamento e organização de informações representadas de várias formas, como textos, vídeos, gráficos, animações e áudios, nos bancos de dados eletrônicos e sistemas multimídia.

No entanto, Reitz, et. al (2011), afirma que:

Um usuário de interface que se esforça para minimizar a carga cognitiva associada às operações para com a interface em si, possui menos recursos cognitivos disponíveis para a realização de suas tarefas. Assim, a instrução deve ser organizada de forma a minimizar a carga cognitiva e a diminuir a sobrecarga da memória de trabalho. 
Nesse sentido, o autor ratifica que a interface deve manter-se com o foco no material educacional, e seu uso deve utilizar o mínimo possível da carga cognitiva do aluno. Ter esforço ao utilizar o sistema acarreta uma sobrecarga mental e consequentemente interfere no aprendizado.

Apesar disso, mesmo sabendo que considerar as características do humano e o contexto no qual ele está inserido durante o desenvolvimento de ambientes virtuais de aprendizagem (AVA) é fundamental, haja vista que isso contribua para uma maior aceitação do ambiente por parte do aluno, é válido ressaltar que isso ainda não garante que tais recursos de aprendizagem baseados nas TIC sejam adequados às suas necessidades, ainda que de maneira participativa (ROSA; STRUCHINER, 2010).

\subsection{Design Instrucional}

Define-se Design Instrucional como um conjunto de atividades que possuem a finalidade de identificar um problema ou necessidade de aprendizagem e programar, avaliar e desenhar uma solução para tal (FILATRO, 2008, p. 3). Os fundamentos do Design Instrucional estão baseados nas Ciências Humanas, Ciências da Informação e Ciências da Administração. Além de um processo, o Dl é uma teoria, um ambiente de conhecimento proposto por pesquisas e teorização de estratégias instrucionais. Nesse sentido, ver o design instrucional apenas como uma ciência comportamental, que confia exclusivamente em resultados de aprendizagem passíveis de observação e que deixa de lado aprendizagens mais complexas, é uma maneira bastante simplista de entender como ele efetivamente funciona e quais são seus reais objetivos. Filatro $(2008$, p. 6) afirma que "restringir o DI ao debate das abordagens pedagógicas/andragógicas não é suficiente para o oferecimento de soluções que equilibrem custos, prazos e qualidade". Por isso, reconhecer o DI de maneira integrada e como um novo campo é fundamental. Incorporar uma gama de perspectivas relacionadas à aprendizagem e ao comportamento humano é de extrema importância para definir de qual forma a informação pode ser combinada, processada e apresentada de maneira criativa e precisa, em um contexto histórico, social e organizacional mais amplo. Isso traz, de fato, efetividade para o processo de aprendizagem. Assim, para o desenvolvimento da metodologia proposta para a avaliação de usabilidade do primeiro acesso dos usuários ao curso selecionado, levou-se em conta as competências relacionadas ao campo do $\mathrm{DI}^{11}$, articuladas aos conceitos do design de interação, sob a visão, principalmente, das autoras Rogers, Sharp e Preece (2013).

1 De acordo com o documento Instructional Design Competencies and Performance Statements (2012), publicado pelo International Board of Standards for Training, Performance and Instruction, são 22 competências do Design Instrucional agrupadas em cinco domínios: fundamentos da profissão, planejamento e análise, design e desenvolvimento, avaliação e implementação, gerenciamento. As 22 competências podem ser verificadas a partir de um total de 105 proposições de desempenho que devem ser analisados. 


\subsection{Design de Interação}

Entende-se o Design de Interação por: "projetar produtos interativos para apoiar o modo como as pessoas se comunicam e interagem em seus cotidianos, seja em casa ou no trabalho" (ROGERS; SHARP; PREECE, 2013, p. 8). Isso significa que os produtos interativos existem para criar experiências positivas para os usuários e ampliar a maneira de como as pessoas o utilizam, comunicam-se e interagem. Para as autoras, O Design de Interação engloba teoria, pesquisa e prática no design de experiências de usuário para todos os tipos de tecnologias sistemas e produtos. Ainda, Rogers et al. (2013 p. 10), sugerem que esse processo pressupõe 4 etapas que se inter-relacionam: estabelecer requisitos, criar alternativas de design, prototipar e avaliar. Durante o projeto, essas etapas devem complementar umas as outras e repetir. Envolver os usuários durante as etapas de design torna-se imprescindível para criar soluções condizentes e identificar mudanças que ainda não foram realizadas ou requisitos que não foram atendidos, e é nesta relação que o design participativo e o contexto da experiência do usuário estão inseridos: Para Rogers et al (2013 p. 321):

Envolver os usuários e outros no processo de design significa que os designs e as possíveis soluções precisarão ser transmitidos a outras pessoas, não somente ao designer. Isso exige que o design seja capturado e expresso de uma forma adequada, que permita a revisão, correção e a melhoria. (ROGERS; SHARP; PREECE, 2013, p. 321).

Ainda segundo as autoras:

Uma das principais razões para se buscar um melhor entendimento acerca das pessoas no contexto em que vivem, trabalham e aprendem é que isso pode ajudar os designers a entenderem como projetar produtos interativos que se encaixem nesses nichos (ROGERS; SHARP; PREECE, 2013, p. 15).

Assim, para a finalidade deste trabalho o estudo sobre os conceitos de Design Participativo, Design Centrado no Usuário e Usabilidade são imprescindíveis para a realização de uma avaliação eficaz com o usuário, pois todos eles envolvem a interação como base principal para seu desenvolvimento

\subsection{Design Participativo, Usabilidade e Design Centrado no Usuário}

Segundo Santa Rosa e Moraes (2012), a abordagem do Design Participativo, na qual os usuários atuam como coprojetistas, é adotada com o intuito de melhorar a qualidade do sistema, evitando funções sem utilidade e aumentando o nível de aceitação para um uso mais efetivo do mesmo. Ainda segundo os autores, existem princípios, técnicas e diretrizes que devem ser levadas em consideração pelos designers, além das técnicas correspondentes às atividades de design participativo" (SANTA ROSA; MORAES, 2012, p. 21). O Design Centrado no Usuário [DCU], por sua vez, consiste em uma metodologia que, essencialmente, ajuda a criar sistemas de computação que atendam às necessidades dos usuários (LOWDERMILK, 2013, p. 26). 
Assim, as decisões a respeito do sistema devem ser avaliadas e inseridas de acordo com as necessidades do usuário final e, nesse momento, o DCU assume o papel de ferramenta, o que garante ao produto final uma boa usabilidade, já que este é o seu foco principal.

Ademais, é importante ressaltar a diferença entre DCU e Design Participativo:

Uma das principais diferenças entre o design participativo e a metodologia de design centrado no usuário, é que [no design participativo] o envolvimento dos usuários vai muito além da experimentação ou teste de alternativas de design, ou da participação de métodos qualitativos para medida da satisfação, facilidade de uso ou aceitação. No design participativo, os usuários podem participar do projeto e design como se fizessem parte da equipe de design. (SANTA ROSA E MORAES, 2012, p. 18).

Embora o DCU não envolva os usuários em todas as suas etapas e tome decisões sobre o sistema de modo hierarquizado, não se pode definir entre "certa ou errada" tais abordagens. Cada uma delas é aplicada de acordo com as necessidades específicas de cada projeto. Em ambos contextos, Nielsen e Loranger (2007) entendem usabilidade como:

Um atributo de qualidade relacionado à facilidade de uso de algo. Especificamente, refere-se à rapidez que os usuários podem aprender a usar alguma coisa, a eficiência deles ao usá-lo e quanto lembram daquilo, seu grau de propensão a erros e quanto gosta de utilizá-la (NIELSEN, LORANGER, 2007, p.17).

Nesse sentido, considera-se a usabilidade como uma parte fundamental para o presente estudo, pois é a medida da satisfação do usuário na utilização de algo com o qual interage. Para um produto ou sistema ser bem avaliado por um ser humano, não basta a ele apenas ter todas as funcionalidades, e sim ter essas funcionalidades projetadas tendo em vista os usuários que realizarão a interação com o tal produto ou sistema. Nesse contexto, vale mencionar algumas palavras sobre avaliações de usabilidade de sistemas.

\subsubsection{Avaliações de Usabilidade}

Para obter uma resposta a respeito da usabilidade de um sistema por parte dos usuários, a coleta de feedback pode ser feita de diversas maneiras. É claro que o sujeito que desenvolve o sistema pode somente perguntar aos usuários, pois eles irão, certamente, dizer muito sobre o que está funcionando e o que não está. Porém, isso não dará respaldo para realmente considerar algumas ações como problemáticas. Assim, consideram-se as avaliações de usabilidade fundamentais para quantificar essas observações. Colocar os usuários numa mesma condição de uso determinará de maneira mais fidedigna os problemas do sistema estudado. (LOWDERMILK, 2013, p. 141). Ainda de acordo com o autor, os estudos de usabilidade podem ajudar a fornecer respostas e determinar linhas de base para acompanhar melhorias no design de um sistema. Tais práticas realizadas com os usuários possuem como objetivo geral medir a eficiência de um recurso ou um conjunto de recursos presentes em um 
sistema. Isso é feito por meio de métricas definidas pelo projetista avaliador, como por exemplo, o tempo de execução ou a quantidade de erros, ou até mesmo a combinação das duas. Ele também pode ser planejado para medir aspectos que são difíceis de serem observados, como satisfação e percepção de valor. (LOWDERMILK, 2013).

Neste estudo, para a análise e avaliação de usabilidade, igualmente, foram levados em conta critérios ergonômicos baseados no estudo de Godoi e Padovani (2009), para garantir a utilização do sistema estudado de maneira produtiva, com conforto e segurança em prol do aprendizado significativo. Os critérios são: Condução; Carga de trabalho; Controle explícito do usuário; Adaptabilidade; Gestão de erros; Homogeneidade e coerência; Significado de códigos e denominações; Compatibilidade.

\section{Métodos e processos de avaliação}

O método de avaliação foi estabelecido a partir da combinação de ferramentas utilizadas nas fases de projeto recomendadas nas abordagens do design participativo e DCU. Essas ferramentas de avaliação são aplicadas de maneira sistemática, contando com a participação dos usuários em todo o processo, com o intuito de melhorar a utilização do sistema e a prática educativa (SANTA ROSA \& STRUCHINER, 2010). Vale ressaltar, que todo o processo privilegiou a avaliação dos critérios ergonômicos mencionados.

Num primeiro momento, antes avaliação com os usuários, foi feita uma análise do sistema em estudo por parte dos pesquisadores. Nessa fase foi possível verificar no primeiro acesso ao portal estudado, questões relacionadas ao acesso às informações e à usabilidade, desde o cadastro do usuário, a procura pelo curso selecionado, até o efetivo acesso ao AVA. A medida que os avaliadores avançavam as etapas necessárias para a realização do cadastro no SENAI, bem como para acessar o material online, foi possível verificar que alguns dos critérios ergonômicos selecionados não foram contemplados. A análise foi fundamental para a estruturação do teste feito com os usuários, que estabeleceu uma lista de 8 tarefas para a avaliação de usabilidade. A partir da revisão bibliográfica e dessa 1a fase de avaliação, foram selecionadas ferramentas participativas. $O$ processo foi estruturado em etapas, de acordo com o recomendado por Santa Rosa e Moraes (2012). A Tabela 1 ilustra a organização das fases, as ferramentas utilizadas e a execução desse processo. Vale esclarecer que o processo de avaliação foi executado entre abril e maio de 2017.

Tabela 1: Fases da análise do sistema em estudo

\begin{tabular}{|c|c|c|}
\hline Fases & Ferramentas e tecnicas & Execuçao \\
\hline Recrutamento & $\begin{array}{l}1 \text { fase da avaliacalo } \\
\text { cooperativa } \\
\text { Questionario com } 12 \\
\text { perguntas, } 6 \text { questoes } \\
\text { abertas e } 6 \text { questỏes } \\
\text { fechadas. }\end{array}$ & $\begin{array}{l}\text { Pnmeiro contato com o } \\
\text { grupo por meio de e-mal } \\
\text { e redes sociais. } \\
\text { Explicacalo sobre a } \\
\text { avaliacdo. Aplicacdo de } \\
\text { questionario de perfil do } \\
\text { usuário, a fim de } \\
\text { identificar o nivel de } \\
\text { interosse no assunto bem } \\
\text { como a experiencia com } \\
\text { EAD. } \\
\text { Selectio dos usuários }\end{array}$ \\
\hline
\end{tabular}




\begin{tabular}{|c|c|c|}
\hline $\begin{array}{l}\text { Sondagem de } \\
\text { informaç } \delta \text { es }\end{array}$ & 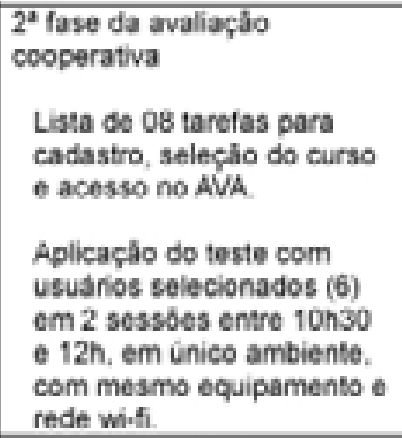 & $\begin{array}{l}\text { Processo de avaliaçjo de } \\
\text { cada usuário, a partir da } \\
\text { aplicaçdo da lista de } \\
\text { tarefas. Na sala estavam } \\
\text { apenas o avaliador eo } \\
\text { usuário. }\end{array}$ \\
\hline $\begin{array}{l}\text { Identificaç̧̃o das } \\
\text { necessidades }\end{array}$ & $\begin{array}{l}3^{2} \text { fase da arvaliação } \\
\text { cooperativa } \\
\text { Conversa incividual com } \\
\text { cada usuano participante } \\
\text { Grupo de foco }\end{array}$ & $\begin{array}{l}\text { Conversa com os } \\
\text { usuarios individuaimente } \\
\text { e conversa em grupo } \\
\text { com todos sobre os } \\
\text { problemas encontrados } \\
\text { no sistema. } \\
\text { Levantamento de } \\
\text { sugestöes para soluçấ. }\end{array}$ \\
\hline $\begin{array}{l}\text { Análise das } \\
\text { informaçbes }\end{array}$ & $\begin{array}{l}\text { Tabulaça dos dados } \\
\text { levantados, levando em conta } \\
\text { os criterrios ergonómicos: } \\
\text { conduçto; carga de trabalho; } \\
\text { controle explicito do usuário; } \\
\text { adaptabilidade; gestaso de } \\
\text { erros; homogeneidade e } \\
\text { coeréneia; signifieado de } \\
\text { codigos e denominaçdes; } \\
\text { compatibilidade. }\end{array}$ & $\begin{array}{l}\text { Avaliadores tabularam os } \\
\text { dados coletados, a fim de } \\
\text { identificar e quantificar os } \\
\text { problemas relacionados a } \\
\text { usabilidade. } \\
\text { A relaçlo de problemas } \\
\text { foi analisada a partir dos } \\
\text { criterios ergonomicos. }\end{array}$ \\
\hline Recomendaçóes & $\begin{array}{l}\text { Lista de recomendaç̧es com } \\
\text { sugestốs de redesenho das } \\
\text { pdginas estudadas, com base } \\
\text { nos fundamentos da } \\
\text { linguagem visual. }\end{array}$ & $\begin{array}{l}\text { A partir dos problemas } \\
\text { encontrados, foi possivel } \\
\text { propor recomendaçles } \\
\text { para meinonas do } \\
\text { sistema. } \\
\text { Foram apontadas } \\
\text { sugestdes para } \\
\text { redesenho das páginas. }\end{array}$ \\
\hline
\end{tabular}

Fonte: adaptado de SANTA ROSA e MORAES, 2012

\subsection{Recrutamento}

Santa Rosa e Moraes (2012) afirmam que o recrutamento de participantes, para realização de avaliações de usabilidade, deve ser baseado no perfil dos usuários reais do sistema em estudo. Para esta pesquisa, o sistema avaliado consiste no cadastro e primeiro acesso ao material online do SENAI EAD. Considerando o SENAI como a maior instituição que oferece cursos técnicos e profissionalizantes voltados para indústria da América Latina, o público-alvo tornou-se bastante indefinido, pois qualquer pessoa, que tenha interesse em se profissionalizar na área industrial, torna-se público-alvo dos cursos oferecidos.

Assim, foi necessário selecionar um dos cursos na modalidade EAD ofertados gratuitamente pela instituição. Ao escolher o curso de Empreendedorismo, foi possível definir de maneira mais clara qual o público participaria da avaliação. Foram selecionados jovens estudantes de graduação, que têm interesse na área de comunicação, criatividade e empreendedorismo, e estão ligados, de alguma maneira, a indústria e comércio da região. Deste modo, pôde-se reunir uma parcela de usuários que, além de estarem inseridos no cenário empresarial da cidade, são jovens que podem contribuir de forma proveitosa para o contexto do trabalho. 
O primeiro contato com estes usuários foi por meio de redes sociais e por e-mail, com uma breve explicação sobre o trabalho desenvolvido, sobre os testes aplicados. A partir deste contato, foi possível a formação do grupo, dando início assim, ao estudo com os usuários. É válido ressaltar que todas as informações do perfil dos usuários foram obtidas por meio de um questionário contento 6 perguntas abertas e 6 fechadas, que foi aplicado antes das avaliações individuais. $O$ grupo contou com seis voluntários, sendo eles cinco do gênero feminino e um do gênero masculino. Todos são estudantes de Design na (Nome da universidade), e estão cursando entre o $4^{\circ}$ e 6 períodos. Além disso, todos pertencem ao Movimento Empresa Júnior (MEJ), mais precisamente, empresários juniores da (nome da empresa), empresa criada em 2012, pelos próprios alunos do curso em conjunto com o MEJ. Embora todos tivessem conhecimento sobre os cursos gratuitos oferecidos pelo SENAI, nenhum deles teve nenhuma experiência com a EAD da instituição.

\subsection{Sondagem de informações e análise}

Na segunda etapa do projeto, foi realizada a avaliação cooperativa. Segundo Monk et. al (1993, apud MORAES; SANTA ROSA, 2012, p. 126), a avaliação cooperativa consiste em um "procedimento para obtenção de dados sobre problemas encontrados ao trabalhar com um sistema, de modo a serem feitas alterações que melhorem o produto". Apesar de ser indicada para ser usada nas fases iniciais de um projeto, Moraes e Santa Rosa (2012) afirmam que a avaliação cooperativa também pode ser empregue em um sistema já existente que deva ser melhorado e ampliado, que foi o caso deste trabalho. Ainda segundo os autores, ela difere dos métodos simples de observação, pois envolve os usuários ativamente no processo, verbalizando todos os problemas e situações adversas encontradas.

Assim sendo, as sessões foram operadas durante dois dias da semana, cada dia com três usuários individualmente, todas entre o horário das $10 \mathrm{~h} 30$ e 12h, na mesma sala climatizada. Todo o processo foi filmado. Foram elaboradas oito tarefas simples a respeito das diretrizes de funcionamento do sistema, que serviram de guia/roteiro para os usuários iniciarem a avaliação. Foi pedido que lessem as tarefas em voz alta e executassem no computador, enquanto o avaliador observava e filmava suas ações, deixando claro que a avaliação era o sistema, e não do usuário. Além disso, foi pedido que, à medida que encontrassem problemas ou dificuldades, os usuários verbalizassem essas situações. Vale salientar, que todos utilizaram o mesmo notebook HP Core i3, e a mesma rede de Wi-fi.

A variação de tempo de cada sessão foi bastante surpreendente, pois a mais rápida durou cerca de 9 minutos e a mais longa 20 minutos. Isso mostra que, embora o grupo seja bastante conciso, observar os usuários individualmente é de grande importância para o avaliador, pois o uso do sistema é, em geral, distinto para diferentes pessoas. 


\subsection{Identificação das necessidades}

Após a aplicação das tarefas na fase de avaliação cooperativa, foi realizada uma conversa informal com cada um dos usuários individualmente, a fim de extrair as primeiras impressões a respeito da interface apresentada. Essa conversa informal é a terceira e última etapa do processo. Cada diálogo durou entre três e cinco minutos, tempo suficiente para os usuários relatarem suas opiniões iniciais sobre o sistema.

De modo geral, os participantes observaram muitos problemas durante o uso do sistema. Eles dizem respeito à interface, à programação e ao conteúdo. Dentre as dificuldades encontradas, a hierarquia confusa das informações em praticamente todas as páginas acessadas, a falta de informações e feedback a respeito das tomadas de decisão, ações desnecessárias que consomem a carga cognitiva do usuário e muitos erros inesperados de programação foram as mais mencionadas pelos participantes. Juntos, esses fatores provocam uma ineficiência do sistema como um todo em diversas situações. Tais questões foram igualmente relatadas durante a avaliação em grupo focal.

O grupo focal, por sua vez, permitiu aos participantes uma visão mais profunda a respeito da interface analisada. A etapa foi realizada em 30 minutos e contou a presença de todos os voluntários. Foram apresentados alguns aspectos que serviram de roteiro para a discursão, tais como o perfil dos estudantes EAD, o interesse deles em realizar o curso, quais os principais problemas encontrados e como o design pode ser aplicado para a solução de questões verificadas durante a avaliação.

Após o debate em grupo, foi o momento de sugerir ideias para correção das questões encontradas por eles. Os usuários puderem elaborar juntos, alternativas para melhorar a qualidade do AVA em estudo. Nesta ocasião, todos sugeriram inúmeras ideias, que foram levadas em consideração após a análise ergonômica de cada problema relatado, com a finalidade de recomendar melhorias. Poder discutir o tema uns com os outros, trouxe à tona situações que, para alguns não foram um problema e para outros representaram uma grande dificuldade.

\subsection{Análise das informações}

Nesta etapa, foi possível organizar e quantificar todas as informações prospectadas com usuários, a fim de torná-las conteúdo de análise para as recomendações elaboradas posteriormente. Inicialmente, foram organizadas as informações colhidas na avaliação cooperativa, consideradas relevantes para o trabalho, pois cada usuário relatou individualmente suas primeiras impressões. Foi igualmente necessário identificar quais foram os problemas encontrados, em que circunstâncias se deram tais questões, em qual a página do processo que ocorreram e qual a sua natureza (conteúdo, programação ou interface). Assim, foram criadas tabelas individuais de cada usuário contendo todas essas informações. Elas foram elaboradas a partir dos registros das sessões individuais com os participantes e das anotações feitas pelos avaliadores. Depois da análise, foi possível selecionar somente os problemas relacionados à interface - que são relevantes para o projeto - e, assim, identificar qual o critério 
ergonômico violado por cada um deles, baseado nos critérios propostos por Godoi e Padovani (2009), a saber: Condução; Carga de trabalho; Controle explícito do usuário; Adaptabilidade; Gestão de erros; Homogeneidade e coerência; Significado de códigos e denominações; Compatibilidade. Tais critérios foram importantes para garantir a avaliação do sistema estudado, em prol do uso efetivo, com conforto e segurança e para um aprendizado significativo.

Ao todo, foram evidenciados pelos usuários 13 problemas associados à interface do sistema. É importante ressaltar que, os problemas de interface são acentuados quando estão associados aos de conteúdo e programação, pois o sistema funciona de forma fluida, e é impossível desassociá-los. Ademais, também foi possível verificar a incidência desses problemas, sendo os mais recorrentes, os mais graves encontrados. A Tabela 2 apresenta os problemas identificados pelos usuários e os critérios ergonômicos violados.

\begin{tabular}{|c|c|c|c|c|}
\hline \multicolumn{2}{|c|}{ Problema verificado } & \multirow{2}{*}{$\begin{array}{l}\text { Pagina do Portal } \\
\text { SENA EAD / RN } \\
\text { Plgina } 1 \\
\text { (Site SENA EAD) }\end{array}$} & \multirow{2}{*}{$\begin{array}{l}\begin{array}{l}\text { Ocomencia } \\
\text { (quantidade) }\end{array} \\
5\end{array}$} & \multirow{2}{*}{$\begin{array}{l}\text { Criterio ergondmico } \\
\text { violado } \\
\text { Homogeneidadevooer theis } \\
\text { Significado de codigos e } \\
\text { denominaches }\end{array}$} \\
\hline 1 & $\begin{array}{l}\text { Nao encontrou } \\
\text { botilo } \\
\text { "cadastre-se" }\end{array}$ & & & \\
\hline 2 & $\begin{array}{l}\text { Faltou } \\
\text { informacso } \\
\text { sobre formato } \\
\text { de senha }\end{array}$ & $\begin{array}{l}\text { Psgina } 2 \\
\text { (Dados de Acesso) }\end{array}$ & 1 & Cestlio de entos \\
\hline 3 & $\begin{array}{l}\text { Hierarquia do } \\
\text { cadastro } \\
\text { confusa }\end{array}$ & $\begin{array}{l}\text { Pagina } 3 \text { (Dados do } \\
\text { Certifcado) }\end{array}$ & 1 & Homogeneidadeleoertncia \\
\hline 4 & $\begin{array}{l}\text { O botaso } \\
\text { "anterior" nao } \\
\text { funciona }\end{array}$ & $\begin{array}{l}\text { Pagina } 3 \text { (Dados do } \\
\text { Certifcado) } \\
\text { Pagina } 5 \text { (Termos de } \\
\text { compromisso) }\end{array}$ & 5 & $\begin{array}{l}\text { Controle explicito do } \\
\text { usuario } \\
\text { Conduçą }\end{array}$ \\
\hline 5 & $\begin{array}{l}\text { Campos de } \\
\text { proenchimento } \\
\text { ficarn todos } \\
\text { vermelhos }\end{array}$ & $\begin{array}{l}\text { Phoina } 4 \text { (dados } \\
\text { residenciais } e \\
\text { complementares) }\end{array}$ & 3 & Gestho de erros \\
\hline 6 & $\begin{array}{l}\text { Muitas } \\
\text { informaçoes na } \\
\text { irea de acesso }\end{array}$ & $\begin{array}{l}\text { Phoina } 8 \text { (Acesso as } \\
\text { Ambiente virtual) }\end{array}$ & 1 & $\begin{array}{l}\text { Carga de trabaltho } \\
\text { Adapentilidade }\end{array}$ \\
\hline 7 & $\begin{array}{l}\text { Nab } \\
\text { compreenden } \\
\text { hierarguia dos } \\
\text { cursos }\end{array}$ & $\begin{array}{l}\text { Phoina } 9 \text { (busca por } \\
\text { cursos gratuites) }\end{array}$ & 5 & Homogeneidadeicoertencia \\
\hline 8 & $\begin{array}{l}\text { Nao } \\
\text { compreended } \\
\text { os icones } \\
\text { appesentados }\end{array}$ & $\begin{array}{l}\text { Pagina } 10 \text { (busca pot } \\
\text { cursos gratuitos) e } \\
\text { Pagina } 11 \\
\text { (inseriço no curse) }\end{array}$ & 2 & $\begin{array}{l}\text { Significado de codigos e } \\
\text { denominaçbes }\end{array}$ \\
\hline 9 & $\begin{array}{l}\text { Falta de } \\
\text { foedback so se } \\
\text { inscrever no } \\
\text { curso }\end{array}$ & $\begin{array}{l}\text { Pagina } 11 \\
\text { (inscriçâo no curso) }\end{array}$ & 1 & Cenduçðొ \\
\hline 10 & $\begin{array}{l}\text { Naso encontrou } \\
\text { opsao "curso } \\
\text { comploto", } \\
\text { como indicado } \\
\text { no texto. }\end{array}$ & $\begin{array}{l}\text { Pagina } 12 \\
\text { (Curso completo) }\end{array}$ & 2 & Conduçà \\
\hline 11 & $\begin{array}{l}\text { Texto de } \\
\text { apeosentacsso } \\
\text { nao atrativo }\end{array}$ & $\begin{array}{l}\text { Phgina } 12 \\
\text { (Inleio do curso) }\end{array}$ & 2 & Adaptabilidade \\
\hline 12 & $\begin{array}{l}\text { Interface com } \\
\text { muitos espaços } \\
\text { vazios e } \\
\text { informaços } \\
\text { difusas }\end{array}$ & $\begin{array}{l}\text { Pagina } 12 \\
\text { (Inicio do curso) }\end{array}$ & 1 & $\begin{array}{l}\text { Homogeneidadevcoertencia } \\
\text { Carga de trabalhe }\end{array}$ \\
\hline 13 & $\begin{array}{l}\text { Plbina } \\
\text { desnecessabria }\end{array}$ & $\begin{array}{l}\text { Phoina } 13 \\
\text { (curso completo) }\end{array}$ & 6 & Carga de trabalho \\
\hline
\end{tabular}


A partir da listagem dos problemas e de sua articulação com os critérios ergonômicos, foi possível sugerir recomendações para o redesenho das páginas estudadas do portal, respeitando a identidade visual do SENAI. Embora o artigo não apresente as soluções encontradas, é importante mencionar que, para além das recomendações sugeridas de acordo com os autores estudados, algumas das sugestões foram embasadas em fundamentos da linguagem visual, que contemplam a análise e organização de elementos da interface, a hierarquia visual, legibilidade, entre outros. Os principais autores estudados foram Samara (2011) e Lupton (2006). É importante ressaltar, que nem todos os questionamentos feitos pelos participantes podem ser resolvidos apenas com o redesenho das páginas. Muitas vezes os problemas dizem respeito ao conteúdo e à programação do sistema. Não obstante as recomendações tenham sido realizadas embasadas, sobretudo na avaliação dos usuários, é ainda necessário, no decorrer da pesquisa, um estudo que avalie as propostas desenvolvidas, com o propósito de certificar a validade das recomendações.

\section{Conclusão}

De acordo com o objetivo desta pesquisa, que constituiu a avaliação de usabilidade participativa do cadastro e primeiro acesso ao curso EAD oferecido pelo SENAI, foi possível perceber, inicialmente, que, aplicar diferentes ferramentas participativas combinadas entre si para se prospectar problemas os quais não foi possível perceber inicialmente, dinamizou a utilização do método e ampliou a forma de entender estes problemas junto aos usuários envolvidos. Também é possível considerar que, esse processo participativo permitiu a compreensão de como o papel do usuário em um contexto de projeto é importante. Embora o grupo de voluntários tenha sido bastante conciso, ainda assim, diferentes realidades proporcionaram ao estudo um leque de possibilidades que os avaliadores, sozinhos, não seriam capazes de perceber.

Apesar isso, as recomendações feitas posteriormente a partir dos problemas encontrados, não garantem uma boa usabilidade ao sistema. Para que isso seja pressuposto, é necessário a aplicação de outro teste participativo de usabilidade que avalie as novas interfaces propostas, para assim, verificar se a incidência de erros continua ou até mesmo se surgiu novos erros que dificultem o uso. Isso reafirma, sobretudo, o valor de aprofundar o estudo em métodos e ferramentas de Design Participativo.

Com relação aos problemas encontrados, embora tenham ligação aos critérios ergonômicos sugeridos por Godoi e Padovani (2009), eles convergem para o aprimoramento das informações nas páginas do sistema, o que está diretamente ligado ao design da informação. Outrossim, algumas das questões têm relação à compreensão da terminologia ou tipologia de informação, muitas delas consequência da estrutura organizacional do SENAI.

Por fim, o estudo possibilitou entender que o designer instrucional está inserido no contexto da EAD não só como um profissional qualificado para desenvolver os materiais de estudo a distância, mas sim como um agente transformador, indispensável para promover aos alunos uma aprendizagem e uma experiência significativa no seu contexto real. 


\section{REFERÊNCIAS}

ALVES, Lucinéia. Educação a distância: conceitos e história no Brasil e no mundo. Revista Brasileira de Aprendizagem Aberta e à Distância, v.10, p. 83-92, 2011.

BEHAR, Patrícia Alejandra (Org). Modelos pedagógicos em educação a distância. Porto Alegre: Artmed, 2009.

CASTELLS, Manuel. A sociedade em rede. São Paulo: Paz e Terra, 2012.

FERREIRA, Aurélio. Buarque de Holanda. Novo Aurélio século XXI: o dicionário da língua portuguesa. Rio de Janeiro: Nova Fronteira, 1999.

FILATRO, Andrea. Design Instrucional contextualizado: educação e tecnologia. São Paulo: Editora Senac, 2004.

FILATRO, Andrea. Design Instrucional na prática. São Paulo: Pearson Education do Brasil, 2008.

GODOI, Katia Alexandra de.; PADOVANI, Stephania. Avaliação de material didático digital centrada no usuário: uma investigação de instrumentos passíveis de utilização por professores. Produção, v. 19, n. 3. p. 445-457, 2009.

INTERNATIONAL Board of Standards for Training, Performance and Instruction. Instructional Design Competencies and Performance Statements. Disponível em: http:// ibstpi.org/instructor-competencies/. Acesso em 15 set. 2016.

LOWDERMILK, Travis. Design centrado no usuário: um guia para desenvolvimento de aplicativos amigáveis. São Paulo: Novatec Editora, 2013.

LUPTON, Ellen. Pensar com tipos: guia para designers, escritores, editores e estudantes. São Paulo: Cosac Naify, 2006.

MORAN, José. Mudando a educação com metodologias ativas. In: Coleção Mídias Contemporâneas. Convergências Midiáticas, Educação e Cidadania, São Paulo, v. 2, p. 15-33, 2015.

MUGNOL, Marcio. A EDUCAÇÃO A DISTÂNCIA NO BRASIL: conceitos e fundamentos. Diálogo Educ., Curitiba, v. 9, n. 27, p.335-349, 2009.

NETO, Americo Talarico.; ANACLETO, Junia Coutinho.; NERIS, Vania Paula de Almeida. Padrões para apoiar o projeto de material instrucional para EAD. In: 3은 Latin American Conference on Pattern Languages of Programs. São Paulo: Sugarloaf Plop, 2005. 
NIELSEN, Jakob.; LORANGER, Hoa. Usabilidade na Web: Projetando Websites com Qualidade. Rio de Janeiro: Elservier, 2007.

PORTAL DA INDÚSTRIA. Disponível em: http://www.portaldaindustria.com.br/senai/. Acesso em 02 mai. 2017.

PORTAL MINISTÉRIO DA EDUCAÇÃO / Secretaria de Educação Superior a Distância. Educação Superior a Distância. Disponível em: http://portal.mec.gov.br/instituicoescredenciadas/educacao-superior-a-distancia. Acesso em: 20 mar. 2016.

PORTAL SENAI. Disponível em: http://www.rn.senai.br/. Acesso em 21 mai. 2017.

REITZ, Doris Simone., et al. Avaliação da Usabilidade Técnica e Pedagógica no Desempenho de Alunos em E-Learning. Cadernos de Informática, Rio Grande do Sul, v. 6, n. 1, p.125-132, 2011.

REZENDE, Flávia. As novas tecnologias na prática pedagógica sob a perspectiva construtivista. Ensaio - Pesquisa em Educação em Ciências. Belo Horizonte, v. 2, n. 1, p. 70-87, 2002.

ROGERS, Yvonne.; SHARP, Helen.; PREECE, Jenny. Design de interação: além da interação humano-computador. Tradução por Isabela Gasparini. Porto Alegre: Bookman, 2013.

SAMARA, Timothy. Guia de design editorial: manual prático para o design de publicações. Porto Alegre: Bookman, 2011

SANTA ROSA, José Guilherme.; MORAES, Anamaria de. Avaliação e projeto no design de interfaces. Teresópolis: 2AB, 2012.

SANTA ROSA, José Guilherme.; STRUCHINER, Miriam. Design Participativo de um Ambiente Virtual de Aprendizagem de Histologia. Revista Brasileira de Pesquisa em Educação em Ciências, v. 10, p. 1-19, 2010.

VIGOTSKY, L. S. Pensamento e linguagem. São Paulo: Martins Fontes, 1987. 